\title{
FORMALIZEI, E AGORA? UM ESTUDO DAS PRÁTICAS DE GESTÃO DE MICROEMPREENDEDORES INDIVIDUAIS (MEI)
}

Jean Soares Da Silva ${ }^{1}$

Marcus Vinicius De Oliveira Brasil ${ }^{2}$

${ }^{1}$ Mestrando no Programa de Pós-graduação em Administração da Universidade Federal da Paraíba - PPGA/UFPB

${ }^{2}$ Pós-Doutor em Administração e professor Adjunto da Universidade Federal do Cariri - UFCA 


\section{FORMALIZEI, E AGORA? UM ESTUDO DAS PRÁTICAS DE GESTÃO DE MICROEMPREENDEDORES INDIVIDUAIS (MEI)}

Resumo: O presente trabalho teve como objetivo fazer uma análise das práticas de gestão de microempreendedores individuais da cidade de Juazeiro do Norte - CE. Por meio disso, adotou o método qualitativo, de natureza descritiva e exploratória, caracterizada pelo estudo de caso. Apesar da pesquisa caracterizar-se como qualitativa que, geralmente converge para aplicação de entrevistas, resolveu-se aplicar um questionário para mensurar através de uma escala situações apresentadas ao MEI, de modo que, fosse possível observar o nível de concordância aos questionamentos apresentados e assim caracterizar e interpretar as práticas de gestão. Como resultado, percebeu-se que o MEI possui práticas de gestão bem consolidas principalmente nas dimensões de Organização, Finanças e Marketing.

Palavras-chave: Empreendedorismo. Microempreendedor Individual. Formalização. Gestão de negócios.

\section{$1 \quad$ Introdução}

As discussões relacionadas à temática empreendedora por muito tempo são colocadas em pauta nas discussões de diversos países, isso devido à relevância que a figura do empreendedor vem gerando ao desempenho da economia (MUNIZ; SILVA, 2005). Contudo, a informalidade de alguns empreendedores pode ser prejudicial ao desenvolvimento econômico dos países devido a perda de contribuições tributárias, deslealdade na concorrência e acesso a crédito formal (KENYON; KAPAZ, 2005; BARGAIN; KWENDA, 2010; DAU; CUERVO-CAZURRA, 2014; CORSEUIL; REIS; BRITO, 2015; PONCZEK; ULYSSEA, 2017).

Com a criação da categoria do Microempreendedor Individual - MEI, muitos empreendedores que antes eram informais passaram a se regularizar como microempreendedores formalizados. Em 2018 o número de formalizações como MEI cresceu cerca 1,033 milhão, crescimento de 38\% comparado no mesmo período em 2015 (VEJA, 2018). Nesse sentido, o mercado vai se tornando bastante competitivo para os microempreendedores que pretendem crescer como empresa e o ato da formalizar sua atividade pode não ser necessariamente um fator competitivo no mercado. Sendo assim, o desenvolvimento de uma boa gestão de negócios torna-se nesse contexto algo essencial e indispensável.

Por meio disso, foi levantada a seguinte problemática: como se caracteriza a gestão de microempreendedores individuais que buscam crescer enquanto empresa formal? Desta forma, o objetivo do estudo é fazer uma análise das práticas de gestão de microempreendedores individuais da cidade de Juazeiro do Norte - CE.

Com pouco mais de uma década de existência formal da figura do Microempreendedor Individual, é fato que esse fenômeno ganhou destaque no cenário nacional. Revisando a literatura, Morais e Emmendoerfer (2018) identificaram que muitos dos trabalhos acadêmicos 
costumam investigar as implicações da formalização na receita dos governos e sobre as condições socioeconômicas, outros estudos também apontam para os benefícios da categoria nos indivíduos e para a administração pública.

Analisar a gestão do MEI, portanto, torna-se oportuno para compreender melhor esse fenômeno e fortalecer cada vez mais as teorias abordadas na Administração. Por meio do estudo, é possível propor medidas que colaborem para a valorização da categoria e consequentemente a formulação de estratégias que minimizem os desafios de gestão enfrentados pelo microempreendedor individual, auxiliando-os em seu crescimento.

\section{$2 \quad$ Referencial Teórico}

O empreendedorismo constitui uma temática que não é relativamente nova, principalmente pelo volume de pesquisas sobre o tema. Porém, dependendo do contexto de análise desse fenômeno, as discussões sobre o empreendedorismo ainda podem apresentar oportunidades de pesquisa diversas.

Segundo Morais e Emmendoerfer (2018) o conceito de empreendedorismo pode estar incluso em duas principais correntes de pesquisas: na Administração e na Economia. A primeira perspectiva é voltada para os estudos comportamentais do empreendedor, e a segunda para o empreendedor no sistema econômico e sua relação em torno do ambiente. (MORAIS; EMMENDOERFER, 2018). No presente estudo, assume-se a base conceitual da primeira corrente de pesquisa onde o foco de análise está centrado nas ações empreendedoras.

Para Baggio e Baggio (2014, p. 26) "o empreendedorismo pode ser compreendido como a arte de fazer acontecer com criatividade e motivação". Segundo os autores, o empreendedor é aquele assume um comportamento proativo a frente de questões que necessitam ser resolvidas. Por tal, o empreendedor no exercício de suas atividades empresariais configura-se como um indivíduo de grande importância para o desenvolvimento de um país.

Porém, nos últimos tempos, um dos grandes problemas enfrentados pelo Brasil diz respeito à falta de formalidade dessas atividades empresariais (RAMALHO, 2015). Quando se trata de pequenos negócios, a informalidade pode ser bastante presente na realidade dos empreendedores, principalmente para aqueles que foram motivados por aspectos de necessidade.

As questões que envolvem a informalidade nos negócios já possui uma significativa atenção na literatura (BARGAIN; KWENDA, 2010; KENYON; KAPAZ, 2005; LEONTARIDI, 1998). Por meio disso, políticas públicas que incentivam a formalização dos negócios vêm surgindo nos últimos anos. No Brasil, a simplificação burocrática e a diminuição de taxas e impostos em pequenos negócios, já apresentam efeitos positivos para o desempenho das microempresas (FAJNZYLBER; MALONEY; MONTES-ROJAS, 2011).

Neste sentido, para alavancar ao máximo o desenvolvimento de novos negócios, a Lei Complementar $n^{\circ}$ 128/2008 alterou a Lei Geral da Micro e Pequena Empresa, a saber, Lei Complementar $n^{\circ} 123 / 2006$, e criou a figura do Microempreendedor Individual (MEI), que entrou em vigor a partir de julho de 2009.

Microempreendedor Individual (MEI) 
O Microempreendedor Individual é a pessoa de atividade autônoma que se formaliza como pequeno empresário. É uma categoria de empresa de porte mais simples que abrange a pessoa que trabalha de forma autônoma e que se legaliza para exercer uma atividade econômica de circulação de bens e prestação de serviços. (SEBRAE, 2019). Para ser MEI, o empreendedor só pode faturar um valor máximo de 81.000,00 por ano, não pode ser sócio ou proprietário de outra empresa, e ter no máximo um empregado (PORTAL DO EMPREENDEDOR, 2019).

O MEI tem um processo de obtenção de CNPJ simplificado e sem custos, estão isentos dos tributos federais (IR, PIS, Cofins, IPI e CSLLL) e contribuem apenas com uma alíquota fixa de 5\% sobre o salário mínimo. Tais medidas tendem a estimular significativamente a formalização das atividades empreendedoras elegíveis a essa classificação (CORSEUIL; NERI; ULYSSEA, 2014).

Em virtude dessas questões, o movimento de novos empreendedores registrados como MEI tem crescido intensamente. No relatório sobre o perfil do MEI apresentado pelo Sebrae (2017), em dezembro de 2016 havia cerca de 22 milhões de trabalhadores por conta própria no Brasil, sendo que o MEI registrava 6,6 milhões de inscritos. Dividindo-se o número de MEI's pelo número de trabalhadores por conta própria, chega-se ao indicador do "grau de cobertura". Nesse "grau de cobertura" o MEI saiu de 9,5\% para 30,1\% após quatro anos, ou seja, o nível de formalização triplicou.

Os efeitos da política do MEI ainda estão sendo construídos na literatura, mas já é perceptível como essa categoria é importante para o desenvolvimento social, político e econômico do país. Além de tirar milhões de pessoas da informalidade, a categoria gera garantias previdenciárias para esses empresários individuais a partir do recolhimento financeiro mensal de suas atividades (SOUZA, 2013).

Aos que tiveram a perda de um emprego, empreender formalmente como MEI acaba sendo uma oportunidade para escapar do desemprego e voltar à ativa no mercado de trabalho. Oliveira e Sanabio (2005) já relatavam que, entre as diversas motivações para começar um negócio, o empreendedorismo surge como resposta ao baixo nível de empregos formais. Dessa forma, para manter-se no mercado de trabalho, alguns desempregados encaram o desafio de montar seu próprio negócio, condicionados a uma personalidade empreendedora.

As atividades permitidas ao microempreendedores individuais são estabelecidas segundo o Comitê Gestor do Simples Nacional - CGSN, Anexo XI da Resolução CGSN n. 140/2018. A resolução lista mais de 500 atividades relacionadas ao Comércio, Indústria e Serviço que podem se enquadrar como MEI. Nisso, os indivíduos não precisam necessariamente ter um conhecimento intelectual ou até mesmo regulamentação legal na atividade que atuam (FARIA et. al. 2015). Isso abre possibilidades para que a categoria seja o mais abrangente possível às atividades informais que existam no país.

Para Salgado (2012), a Lei Complementar no 128/2008 trouxe muito mais do que legalidade e tributação para empreendedores que viviam na informalidade, pois oportunizou o acesso a serviços de linhas de créditos, comercialização de produtos e prestação de serviços para órgãos públicos, emissões de documentos fiscais entre outros.

Contudo, devido à dinâmica de mudanças que acontecem constantemente no atual mercado, conduzir uma empresa pode não ser uma tarefa tão simples. Para muitas das empresas consolidadas no mercado, empreender é uma luta constante aos desafios internos e 
externos que afetam diretamente ou indiretamente o ambiente organizacional e seu crescimento. Por meio disso, ter uma conduta empreendedora é o maior requisito para o sucesso de uma empresa. (CUSTODIO, 2011).

Para Pelissari et al. (2012) quando se tem um negócio, independente da dimensão, o empreendedor acaba inserido em um mercado que é caracterizado pela economia e por uma intensa competitividade de produtos e serviços. Sendo assim, mesmo que o MEI tenha seus benefícios na redução de burocracias, para os empreendedores que desejam crescer como empresa não baste apenas formalizar sua atividade, após a formalização, a boa gestão de negócios torna-se algo indispensável para o bom desempenho e sobrevivência do empreendimento.

\section{MEI e os desafios de gestão}

Apesar da realidade empresarial dos microempreendedores não ser tão complexa quando comparada com empresas de médio e grande porte, a gestão empresarial é um fator inerentes em seu dia a dia. Muitas vezes o microempreendedor está "sozinho" no seu empreendimento e desempenha funções múltiplas em seu negócio, por tanto, é provável que não seja comum a existência de uma estrutura empresarial sólida.

A mudança no ambiente econômico em consonância com os comportamentos de consumo e rivalidade da concorrência exige do MEI atenção na forma como administra seu negócio. Para Pelissari et al. (2012) a sobrevivência para esses empreendimentos depende bastante da formulação de boas estratégias, apoiada em inovação e criatividade, e em conhecer o ambiente para perceber as oportunidades e ameaças ao redor.

Conforme Cruz (2005) o segredo para uma boa gestão não está necessariamente em um modelo e na cópia deste, mas sim na avaliação das situações, problemas e contextos, e então, uma operacionalização das medidas empresariais que influenciarão na tomada de decisão. Ao grande número de empreendedores que saíram da informalidade, o questionável é que existem desafios para serem superados a cada novo estágio no processo de empreender um negócio.

A partir de uma revisão da literatura no contexto de pequenas e médias empresas brasileiras, North, Neto e Calle (2013) identificaram alguns desafios para o crescimento desses negócios. Questões como, obtenção de recursos para financiar operações e planos; processo de planejamento estratégico e decisões corretas; diferenciação da concorrência; atualização tecnológica - integração de sistemas de gestão; e habilidade para lidar com situações novas (capacidade dinâmica) foram pontuados como alguns desafios à serem superados (NORTH; NETO; CALLE, 2013). Acredita-se que tais desafios também não sejam distantes da realidade de microempreendedores individuais.

No mesmo contexto, Tavares, Ferreira e Carvalho Lima (2009) desenvolveram uma escala de mensuração para identificação das práticas de gestão das micro e pequenas empresas. A operacionalização do estudo foi orientada pelas dimensões de planejamento, organização, finanças, marketing e pessoas. O objetivo era perceber quais procedimentos utilizados pelas microempresas se eram adequadamente estruturados para um bom desempenho organizacional. 
Quadro 1 - Dimensões da gestão de negócios

\begin{tabular}{|c|l|}
\hline Dimensões & \multicolumn{1}{c|}{ Descrição } \\
\hline Planejamento & $\begin{array}{l}\text { Considera a busca de informações (e o uso de tecnologia) para decisão e o estabelecimento } \\
\text { de metas e planos. }\end{array}$ \\
\hline Organização & $\begin{array}{l}\text { Considera a divisão das tarefas, o planejamento das rotinas, a organização do espaço e } \\
\text { aspectos legais e normativos. }\end{array}$ \\
\hline Finanças & $\begin{array}{l}\text { Considera aspectos relativos à existência de técnicas básicas de gestão financeira, } \\
\text { utilização de informações financeiras e critérios de eficiência financeira. }\end{array}$ \\
\hline Marketing & $\begin{array}{l}\text { Considera aspectos relativos a orientação para o mercado, produto (ou serviço), preço, } \\
\text { localização e promoção. }\end{array}$ \\
\hline Pessoas & $\begin{array}{l}\text { Considera aspectos relativos a comunicação, Remuneração, Relacionamento, treinamento e } \\
\text { capacitação. }\end{array}$ \\
\hline
\end{tabular}

Fonte: Elaborado pelos autores a partir de Tavares, Ferreira e Carvalho Lima (2009, p. 17-18)

As dimensões de gestão apresentadas por Tavares, Ferreira e Carvalho Lima (2009) não induz necessariamente que essas sejam as únicas dimensões de um contexto empresarial. Contudo, no estudo exploratório da literatura para o desenvolvimento desse trabalho, as dimensões de gestão ora apresentadas frequentemente são as mais abordadas no contexto dos microempreendedores individuais (LOPES et al., 2014; SOUZA et al., 2014; ANDRADE; BOFF, 2014; FERNANDES SILVA et al., 2014; SOUZA et al., 2015; MATURANA et al., 2015; MATURANA; BAGGIO, 2016; MANTOVANI; CADONÁ, 2017; DA ANUNCIAÇÃO et al., 2018; DA SILVA; SPANHOL; DE SOUZA, 2018; DOS SANTOS et al., 2019; DIAS MANGUEIRA; LAPA, 2019) Em suma, o estudo dessas dimensões no contexto do microempreendedor individual são abordadas em sua maioria de modo independente.

Na dimensão de Planejamento, Andrade e Boff (2014) através de um estudo de caso, buscaram analisar e identificar quais foram os procedimentos de implantação de uma ferramenta para um MEI prestador de serviços de entrega. Como resultado, os autores evidenciaram a necessidade de ferramentas mais eficazes que contribuam para a tomada de decisão.

Na dimensão da Organização, Da Anunciação et al. (2018) buscaram analisar como acontece o controle de microempreendedores ligados à atividade de artesanato, na cidade de João Pessoa/PB, após a formalização como MEI. Os autores observaram que os empreendedores já realizavam controle organizacional, porém, não conhecem o valor efetivo das contas a pagar, a receber e do estoque, demonstrando que esse controle pode vir a ser falho e não gera informações úteis para esses artesãos.

$\mathrm{Na}$ dimensão Financeira, Lopes et al. (2014) tiveram como objetivo verificar a existência de associações entre as características do MEI e suas práticas de controles financeiros e não financeiros nos negócios. Os resultados indicaram a existência de associações entre as práticas adotadas e suas características, sendo elas: renda mensal com o controle de contas a pagar e formação de preço de venda, também o nível de escolaridade com a prática de controle de contas a receber e idade com o método de decisão de oferta de novos produtos e serviços.

Na dimensão do Marketing, Souza et al. (2015) identificaram estratégias de marketing informal desenvolvidas por microempreendedores de uma feira-livre, no Centro da cidade de Maceió/AL. Percebeu-se nos empreendedores a utilização de compostos de marketing em seu 
dia a dia, e que conseguiam desenvolver empiricamente conhecimentos específicos e lógicos sobre gestão mercadológica.

Por fim, na dimensão de Pessoas, no estudo desenvolvido por Da Silva, Spanhol e De Souza (2018) os autores analisaram o uso do Mobile Learning para a capacitação de MEI. Como resultado, foi evidenciado que a metodologia é uma alternativa inovadora e capaz de viabilizar ao MEI atividades de capacitação, preparando-os assim para atuação num mercado competitivo no qual a inovação assume local de destaque.

Neste sentido, percebe-se que essas cinco dimensões da gestão estão vinculadas aos microempreendedores individuais, portanto, podem ser considerados desafios a serem superados para o bom desenvolvimento de seus negócios, principalmente para aqueles que têm pretensão de crescer enquanto empresa, dado que não basta apenas formalizar o negócio, é necessário geri-lo.

\section{$3 \quad$ Metodologia}

A fim de alcançar o objetivo proposto, o presente estudo adota o método qualitativo, de natureza descritiva e exploratória, caracterizada pelo estudo de caso. De acordo com Godoy (1995, p. 62) "os estudos denominados qualitativos têm como preocupação fundamental o estudo e a análise do mundo empírico em seu ambiente natural".

A proposta deste trabalho é estudar casos específicos de microempreendedores individuais que reconhecem em suas práticas desenvolver gestão de negócios, por tanto, a escolha pelo o estudo de caso apresentou-se coerente para essa pesquisa. Conforme Yin (2005) o estudo de caso é recomendado quando o pesquisa pretender responder questões relacionadas aos processos da empresa. Além disso, os casos proporcionam ao pesquisador aprofundar os conhecimentos sobre o tema em seu contexto (RAUPP; BEUREN, 2006). Como a pesquisa é direcionada para mais de um indivíduo ou organização, ela é caracteriza como estudo de casos múltiplos (VENTURA, 2007).

O contexto de investigação foram alguns Microempreendedores Individuais da cidade de Juazeiro do Norte, pertencente à Região Metropolitana do Cariri - RMC, interior do Estado do Ceará. Considerando que o Sebrae da cidade atende diariamente grande parcela desse público, com autorização prévia da organização, o pesquisador abordava os microempreendedores que se encontravam na empresa para realizar algum atendimento. Nesse momento eram apresentados os objetivos da pesquisa com o intuito de identificar o perfil dos empreendedores e selecionar os mais coerentes para o estudo: microempreendedores formalizados a mais de dois anos que acreditassem possuir práticas de gestão dentro das dimensões ora já abordadas na literatura.

Para identificar os melhores perfis, foram abordados aleatoriamente 38 microempreendedores individuais. Como o trabalho pretendia estudar as práticas de gestão desses empreendedores, percebeu-se que muitos não demonstravam interesse de participar da pesquisa por alegarem não possuir práticas de gestão em seu dia a dia. Sendo assim, dos 38 microempreendedor apenas 5 atendiam ao perfil desejado e foram considerados suficientes para aplicação do método de pesquisa. 


\section{Quadro 2 - Perfil dos Microempreendedores Individuais participantes da pesquisa}

\begin{tabular}{|c|c|c|c|c|c|c|}
\hline MEI & Sexo & Idade & Escolaridade & $\begin{array}{c}\text { Setor de } \\
\text { atuação }\end{array}$ & $\begin{array}{c}\text { Tempo de } \\
\text { atuação da } \\
\text { empresa } \\
\text { formal }\end{array}$ & $\begin{array}{c}\text { Principal motivo que } \\
\text { levou à formalização } \\
\text { como MEI }\end{array}$ \\
\hline MEI A & Feminino & $46-55$ & $\begin{array}{c}\text { Médio } \\
\text { incompleto }\end{array}$ & Indústria & +de 7 anos & $\begin{array}{c}\text { Crescer como empresa } \\
\text { formal }\end{array}$ \\
\hline MEI B & Feminino & $46-55$ & Pós-graduação & Comércio & + de 7 anos & $\begin{array}{c}\text { Crescer como empresa } \\
\text { formal }\end{array}$ \\
\hline MEI C & Masculino & $18-25$ & $\begin{array}{c}\text { Superior } \\
\text { incompleto }\end{array}$ & Serviço & 1 a 2 anos & $\begin{array}{c}\text { Crescer como empresa } \\
\text { formal }\end{array}$ \\
\hline MEI D & Masculino & $26-35$ & Médio completo & Serviço & + de 7 anos & Benefícios INSS \\
\hline MEI E & Masculino & $18-25$ & $\begin{array}{c}\text { Superior } \\
\text { incompleto }\end{array}$ & Comércio & 3 a 4 anos & $\begin{array}{c}\text { Crescer como empresa } \\
\text { formal }\end{array}$ \\
\hline
\end{tabular}

Fonte: Elaborado pelos autores com dados da pesquisa (2019)

Conforme Creswell (1994) no método de pesquisa qualitativa diversas estratégias podem ser utilizadas para coleta, análise e confecção de relatórios de resultados, a adaptação das estratégias depende do interesse do pesquisador para resolução do seu problema de pesquisa. Sendo assim, a técnica utilizada para coleta de dados foi associada a pesquisa de campo por meio de um questionário aplicado aos cinco microempreendedores individuais.

Apesar da pesquisa caracterizar-se como qualitativa que, geralmente converge para aplicação de entrevistas, resolveu-se aplicar um questionário para mensurar através de uma escala situações apresentadas aos participantes, de modo que, fosse possível observar o seu nível de concordância ao questionamentos apresentados e assim caracterizar e interpretar suas práticas de gestão.

O questionário era composto de 25 afirmativas tendo como referência algumas dimensões da gestão empresarial, conforme já apresentadas na construção teórica: planeamento, organização, finanças, marketing e pessoas. As questões foram delineadas a partir do estudo exploratório de modo que pudesse ser sustentadas teoricamente. Antes de ir ao campo, o questionário já tinha passado por um pré-teste.

As afirmações foram respondidas em uma escala de 4 pontos de concordância, sendo estes: (1) Discordo Totalmente, (2) Discordo, (4) Concordo e (5) Concordo Totalmente. O ponto neutro que em uma escala comum de 5 pontos seria o (3) foi retirado das possibilidades de respostas. Conforme apresentam Guy e Norvell (1977) o ponto neutro induz os participantes a fugirem dos extremos e em grande parte utilizarem os pontos médios nas respostas. Para Lucian (2016) o ponto neutro só faz anular a escala e a recomendação é retirar esse ponto para não apresentar uma análise neutra nas afirmações.

Os questionários aplicados aos cinco microempreendedores individuais aconteceram de 30 de abril a 14 de maio de 2018. Conforme Teixeira (2003) após a coleta de dados a pesquisa seguiu as fases de análise e interpretação, mesmo sendo conceitualmente distintos, ambos estão estreitamente relacionados.

A análise seguiu os pressupostos da análise de conteúdo de Bardin (1979). Para o autor, a análise de conteúdo visa "obter, por procedimentos sistemáticos e objetivos de descrição do conteúdo mensagens, indicadores (quantitativos ou não) que permitam a inferência de conhecimentos relativos às condições de produção/recepção destas mensagens" (1979, p. 42). 


\section{$4 \quad$ Resultados e Discussões}

A partir das respostas dos microempreendedores individuais foi possível organizar os dados da pesquisa em tabelas para melhor compreender as características de sua gestão. Para facilitar a apresentação e contextualização dos resultados às cinco dimensões investigadas (planejamento, organização, finanças, marketing e pessoas) encontram-se detalhadas à seguir:

Tabela 1 - Análise das práticas de gestão na dimensão Planejamento

\begin{tabular}{|l|l|c|c|c|c|c|}
\hline \multicolumn{1}{|c|}{ Questionamentos } & $\begin{array}{c}\text { MEI } \\
\text { A }\end{array}$ & $\begin{array}{c}\text { MEI } \\
\text { B }\end{array}$ & $\begin{array}{c}\text { MEI } \\
\text { C }\end{array}$ & $\begin{array}{c}\text { MEI } \\
\text { D }\end{array}$ & $\begin{array}{c}\text { MEI } \\
\text { E }\end{array}$ \\
\cline { 2 - 7 } & $\begin{array}{l}\text { Meu negócio possui um planejamento estratégico ou plano de } \\
\text { negócio. }\end{array}$ & 4 & 1 & 5 & 5 & 5 \\
\cline { 2 - 7 } & $\begin{array}{l}\text { Possuo metas e ações definidas e registradas para o } \\
\text { empreendimento. }\end{array}$ & 4 & 4 & 5 & 2 & 4 \\
\hline & $\begin{array}{l}\mid \\
\text { Planejo um dia mudar da categoria MEI para ME. }\end{array}$ & 1 & 1 & 5 & 1 & 5 \\
\cline { 2 - 7 } & $\begin{array}{l}\text { Possuo um planejamento de compras/produção baseado no } \\
\text { que espero vender. }\end{array}$ & 4 & 5 & 5 & 1 & 5 \\
\cline { 2 - 7 } & $\begin{array}{l}\text { As decisões finais da empresa são pontuadas diretamente por } \\
\text { mim. }\end{array}$ & 5 & 5 & 5 & 5 & 4 \\
\hline
\end{tabular}

*1 Discordo Totalmente; 2 Discordo; 4 Concordo; 5 Concordo Totalmente

Fonte: Elaborado pelos autores com dados da pesquisa (2019)

Considerando-se as práticas dos microempreendedores no planejamento de suas atividades, foram levantadas questões sobre planejamento estratégico, definição de metas, perspectivas de migração, planejamento de compras e decisões no empreendimento. Para Figueiredo e Caggiano (2004), as práticas de planejamento são as mais básicas nas atividades de gestão, para o autor, a competência nessa dimensão contribui para o sucesso das outras operações.

$\mathrm{Na}$ análise, os microempreendedores demonstram concordar em níveis próximos para a maioria das práticas apresentadas, pois em sua maioria o nível de concordância é total. Dos cinco microempreendedores, quatro concordam que possui um planejamento estratégico ou plano de negócio, o que é algo positivo para o empreendimento. Não se afirma ao certo se o planejamento estratégico é formal ou informal.

Meyer (1997) acredita que, independente do porte, as empresas costumam possuir um planejamento, alguns são formalizados e escritos e outros podem existir apenas na mente do empreendedor. Porém, acredita-se que na maioria dos casos aqui apresentados, os microempreendedores possuam um planejamento formal, dado que, muitos também concordam que possui metas e ações definidas e registadas, e um planejamento de compras/produção no que espera vender.

Contudo, no planejamento de mudar de categoria MEI para Microempresa (ME), três dos quatro empreendedores não se mostraram muito interessados em mudar de categoria, situação que pode ser explicada pelos benefícios que o MEI oferece: redução de taxas, isenção de impostos e licenças, e outras facilidades. Ou seja, mesmo que a empresa prospere além do esperado e faça vendas além do permitido na categoria (máximo de $81.000 \mathrm{R} \$$ por ano), pode acontecer de muitos empreendedores continuarem como MEI sem mais enquadrar-se na categoria. 
Tabela 2 - Análise das práticas de gestão na dimensão Organização

\begin{tabular}{|l|l|c|c|c|c|c|}
\hline \multicolumn{1}{|c|}{ Questionamentos } & $\begin{array}{c}\text { MEI } \\
\text { A }\end{array}$ & $\begin{array}{c}\text { MEI } \\
\text { B }\end{array}$ & $\begin{array}{c}\text { MEI } \\
\text { C }\end{array}$ & $\begin{array}{c}\text { MEI } \\
\text { D }\end{array}$ & $\begin{array}{c}\text { MEI } \\
\text { E }\end{array}$ \\
\cline { 2 - 7 } & $\begin{array}{l}\text { A organização do meu negócio me permite trabalhar de } \\
\text { maneira eficiente e ágil. }\end{array}$ & 5 & 5 & 5 & 5 & 4 \\
\cline { 2 - 7 } & $\begin{array}{l}\text { Costumo ter um espaço reservado para produção, } \\
\text { comercialização ou organização de materiais que utilizo na } \\
\text { minha atividade. }\end{array}$ & 4 & 5 & 1 & 5 & 2 \\
\cline { 2 - 7 } & $\begin{array}{l}\text { Controlo quem são os fornecedores de meus produtos e } \\
\text { prestadores de serviço, para facilitar a pesquisa de preço. }\end{array}$ & 1 & 5 & 4 & 5 & 5 \\
\cline { 2 - 7 } & $\begin{array}{l}\text { Utilizo algum software (programa de computador) ou } \\
\text { aplicativo em celular para melhor gestão do meu negócio. }\end{array}$ & 1 & 1 & 5 & 5 & 5 \\
\hline $\begin{array}{l}\text { Os documentos importantes de minha empresa estão bem } \\
\text { organizados e guardados. }\end{array}$ & 5 & 5 & 5 & 5 & 5 \\
\hline
\end{tabular}

*1 Discordo Totalmente; 2 Discordo; 4 Concordo; 5 Concordo Totalmente

Fonte: Elaborado pelos autores com dados da pesquisa (2019)

Nas práticas relacionadas à organização do empreendimento, os microempreendedores foram questionados sobre a organização do seu ambiente de trabalho considerando a eficiência e agilidade, organização de espaços físicos, controle de fornecedores, utilização de ferramentas e softwares, e organização de documentos importantes. Conforme Carvalho (2013) o controle efetivo da organização é importante para as empresas garantirem sua permanência no mercado e evolução econômica.

A análise foi bastante positiva para todas as situações apresentadas, visto que, no mínimo três dos cinco empreendedores participantes concordavam ou concordavam totalmente com as situações apresentadas. Para os níveis mais baixos de resposta, ou seja, discordância total, apenas um microempreendedor demonstra não possuir um espaço reservado para produção, comercialização ou organização dos materiais que utilizada, e dois microempreendedores demonstram não utilizarem algum software ou aplicativo para auxílio na gestão.

Considerando-se o avanço tecnológico e a forma como as atividades empresariais vêm sendo informatizadas, ferramentas e aplicativos podem ajudar muito os microempreendedores. Mesmo que a as atividades do MEI sejam mais simples, o Portal do Empreendedor em parceria com o Sebrae já dispõe para esse público uma série de ferramentas e aplicativos que contribuem na gestão.

Tabela 3 - Análise das práticas de gestão na dimensão Finanças

\begin{tabular}{|c|c|c|c|c|c|c|}
\hline \multirow{6}{*}{ 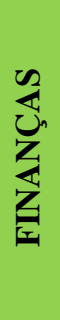 } & Questionamentos & $\begin{array}{c}\text { MEI } \\
\text { A } \\
\end{array}$ & $\begin{array}{c}\text { MEI } \\
\text { B } \\
\end{array}$ & $\begin{array}{c}\text { MEI } \\
\mathrm{C}\end{array}$ & $\begin{array}{c}\text { MEI } \\
\text { D } \\
\end{array}$ & $\begin{array}{c}\text { MEI } \\
\mathbf{E} \\
\end{array}$ \\
\hline & Controlo as entradas e saídas de dinheiro. & 5 & 5 & 5 & 5 & 5 \\
\hline & Pago o boleto do DAS sempre em dias. & 5 & 5 & 5 & 2 & 5 \\
\hline & Calculo os gastos (custos e despesas) mensalmente. & 5 & 5 & 5 & 5 & 5 \\
\hline & Calculo os lucros e prejuízos do meu negócio periodicamente. & 5 & 5 & 5 & 5 & 5 \\
\hline & $\begin{array}{l}\text { Separo minhas finanças pessoais das finanças do meu } \\
\text { empreendimento. }\end{array}$ & 5 & 5 & 4 & 2 & 5 \\
\hline
\end{tabular}

*1 Discordo Totalmente; 2 Discordo; 4 Concordo; 5 Concordo Totalmente

Fonte: Elaborado pelos autores com dados da pesquisa (2019) 
Em análise às práticas Financeiras, os empreendedores foram questionados sobre os controles de entrada e saídas de dinheiro, pagamentos em dias das obrigações como MEI, cálculo de gastos e despesas, lucro e prejuízos, e separação de finanças pessoais e do negócio. Segundo Bittencourt e Palmeira (2012) as prática de gestão financeira são essenciais para um sucesso sustentável e sua perpetuidade.

Bueno (2003) apresenta que, na maioria das micro e pequenas empresas as ferramentas de gestão financeiras são pouco utilizados. Quando se trata de alguns controles como: controle de caixa, estoque, contas a pagar e receber, infelizmente, são procedimentos quase inexistentes na micro e pequena empresa. Porém, a concordância dos microempreendedores para a gestão financeira nessa pesquisa é alta, quase todos os valores atribuídos pelos respondentes correspondem a uma concordância total, isso mostra que os empreendedores possuem, ou pelo menos acreditam possuir uma boa gestão financeira.

Para os níveis mais baixos de resposta, apenas um empreendedor apresenta em seu questionário que algumas vezes não faz o pagamento de suas contribuições como MEI em dias, e que não separa totalmente suas finanças pessoais do negócio. Para esse contexto, era esperado que algum microempreendedor não fosse tão efetivo nessa prática devido a manutenção de suas atividades pessoais que muitas vezes "força" o empreendedor a não ser tão efetivo em seu controle financeiro misturando consta da empresa com a vida pessoal e como consequência atrasando algumas contas referentes ao seu negócio. Mesmo não sendo significativa para os outros microempreendedores, uma atenção maior deve ser dada para essa prática.

Tabela 4 - Análise das práticas de gestão na dimensão Marketing

\begin{tabular}{|c|c|c|c|c|c|c|}
\hline \multirow{6}{*}{ 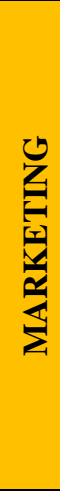 } & Questionamentos & $\begin{array}{c}\text { MEI } \\
\text { A }\end{array}$ & $\begin{array}{c}\text { MEI } \\
\text { B } \\
\end{array}$ & $\begin{array}{c}\text { MEI } \\
\text { C }\end{array}$ & $\begin{array}{c}\text { MEI } \\
\text { D } \\
\end{array}$ & $\begin{array}{c}\text { MEI } \\
\text { E } \\
\end{array}$ \\
\hline & Faço pesquisa para saber a satisfação dos meus clientes. & 5 & 1 & 4 & 2 & 4 \\
\hline & $\begin{array}{l}\text { Utilizo ferramentas como: cartão de visita, banners, panfletos, } \\
\text { redes sociais ou outros, para promover e divulgar meus } \\
\text { produtos/serviços. }\end{array}$ & 5 & 5 & 2 & 5 & 5 \\
\hline & Sei quem são e onde estão meus principais concorrentes. & 5 & 1 & 5 & 5 & 4 \\
\hline & $\begin{array}{l}\text { Meu negócio possui nome fantasia/marca para se apresentar } \\
\text { aos clientes. }\end{array}$ & 5 & 5 & 2 & 5 & 5 \\
\hline & $\begin{array}{l}\text { Costumo analisar as tendências de mercado de meu setor de } \\
\text { atuação buscando melhorar minhas atividades sempre que } \\
\text { possível. }\end{array}$ & 1 & 5 & 4 & 4 & 2 \\
\hline
\end{tabular}

*1 Discordo Totalmente; 2 Discordo; 4 Concordo; 5 Concordo Totalmente

Fonte: Elaborado pelos autores com dados da pesquisa (2019)

Quanto às práticas de Marketing, buscou-se observar a relação dos microempreendedores com os clientes, a utilização de soluções de comunicação para divulgar o empreendimento, conhecimentos do mercado, identificação empresarial e análise das tendências de mercado. Para Souza et al. (2015) a gestão de marketing é uma dimensão que não se restringe somente a gestores especializados, mas é uma atividade aberta a microempreendedores que também não possuem conhecimentos acadêmicos sobre gestão, mas, são eficientes para perceber e desenvolver estratégias mercadológicas eficientes.

No que tange a comunicação e identidade do empreendimento, os microempreendedores possuem um nome fantasia/marca para apresentação do negócio e utilizam ferramentas de 
cartão de visita, banners, panfletos, redes sociais ou outras, para promover e divulgar seus produtos/serviços. Para Pimentel (2007) e Santos (2008) o cotidiano do ambiente empresarial influi nos processos cognitivos do indivíduo fazendo-o desenvolver potencialidades relacionadas às capacidades e habilidades da gestão estratégica de marketing.

Referente às práticas de pesquisas para saber a satisfação dos clientes, percebeu-se uma variedade nas respostas dos microempreendedores com valores que atendiam do primeiro ao último ponto extremo da escala. Certamente os empreendedores buscam compreender a satisfação de seus clientes, mas pode acontecer desse processo ser mais informal através de conversas e feedbacks rápidos, o que dificulta o registro de informações e posterior análise para tomada de decisão.

Dos cinco microempreendedores, três concordam que costumam analisar as tendências de mercado do setor de atuação e que buscam por meio dessa análise fazer melhorar nas atividades, e quatro concordam que conhecem seus concorrentes. Conforme Brettel, Strese e Flatten (2012), conhecer a dinâmica do ambiente competitivo aumenta as potencialidades dos resultados mercadológicos e contribui para o marketing da empresa. Nisso, os microempreendedores parecem caminhar bem.

Tabela 5 - Análise das práticas de gestão na dimensão Pessoas

\begin{tabular}{|l|l|c|c|c|c|c|}
\hline \multicolumn{1}{|c|}{ Questionamentos } & \multicolumn{1}{|c|}{$\begin{array}{c}\text { MEI } \\
\text { A }\end{array}$} & $\begin{array}{c}\text { MEI } \\
\text { B }\end{array}$ & $\begin{array}{c}\text { MEI } \\
\text { C }\end{array}$ & $\begin{array}{c}\text { MEI } \\
\text { D }\end{array}$ & $\begin{array}{c}\text { MEI } \\
\text { E }\end{array}$ \\
\cline { 2 - 6 } & Possuo experiências e conhecimentos na área que atuo. & 5 & 4 & 5 & 5 & 4 \\
\cline { 2 - 6 } & $\begin{array}{l}\text { Além de mim, tem outras pessoas que me ajudam nas } \\
\text { atividades do empreendimento. }\end{array}$ & 4 & 1 & 1 & 5 & 5 \\
\cline { 2 - 6 } \\
$\begin{array}{l}\text { Possuo funcionário formalmente registrado com carteira } \\
\text { assinada. }\end{array}$ & 1 & 1 & 1 & 1 & 1 \\
\cline { 2 - 6 } & $\begin{array}{l}\text { Já realizei algum curso/oficina de capacitação para melhorar a } \\
\text { gestão do meu negócio. }\end{array}$ & 5 & 5 & 5 & 5 & 5 \\
\cline { 2 - 7 } & Sei o que fazer para me aposentar com tranquilidade. & 4 & 5 & 5 & 4 & 4 \\
\hline
\end{tabular}

*1 Discordo Totalmente; 2 Discordo; 4 Concordo; 5 Concordo Totalmente

Fonte: Elaborado pelos autores com dados da pesquisa (2019)

Considerando-se as práticas dos microempreendedores para a gestão de pessoas, para esse estudo levou-se como análise principal a autogestão, dado que, o ambiente de pessoas do microempreendedor individual é restrito. A categoria do MEI só permite no máximo um empregado formalizado, por tanto, muitos realizam suas atividades sozinhos ou quando possuem mais de duas pessoas envolvidas na atividade, isso acontece de modo informal.

Quando questionados sobre suas experiências e conhecimentos, todos os microempreendedores concordam que já possuíam experiência sobre seu setor. Para Bitencourt (2001) as experiências conduzem conhecimentos aos indivíduos transformados em ações práticas que configuram aprendizagem. Além disso, os microempreendedores já realizaram curso ou oficinas de capacitação para melhorar a gestão do seu negócio, como também conhecem seus direitos enquanto contribuinte. Isso mostra que o conhecimento é algo presente em sua realidade e pode contribui muito para o bom desempenho nas demais atividades do negócio.

Todos os microempreendedores afirmam não possuírem funcionários. Quando questionados sobre o apoio de outras pessoas nas atividades do empreendedor, três dos 
empreendedores concordam que possui o auxílio de outras pessoas nas atividades. Não foi confirmado ao certo na pesquisa quem seriam essas pessoas, como funcionários informais ou parentes próximos (filhos, cônjuge, irmãos e outros). Porém, a análise induz que os microempreendedores mesmo que possua o apoio de outras pessoas, esse auxílio é caraterizado por um vínculo é informal.

Tomando como referência os procedimentos de análise sobre as práticas de gestão do MEI, o Quadro 3 sintetiza as principais práticas de gestão consolidadas na realidades desses microempreendedores e algumas práticas que, mesmo já sendo desenvolvidas por alguns, podem ser reforçadas como sugestão e alerta para outros empreendedores.

Quadro 3 - Síntese das práticas de gestão dos microempreendedores individuais

\begin{tabular}{|c|c|}
\hline Práticas consolidadas & Práticas que podem ser mais desenvolvidas \\
\hline $\begin{array}{l}\text { 1. Planejamento do negócio; } \\
\text { 2. Decisões pontuadas pelo empreendedor; } \\
\text { 3. Organização do ambiente e dos principais } \\
\text { documentos do negócio; } \\
\text { 4. Utilização de ferramentas tecnológica para } \\
\text { gestão; } \\
\text { 5. Controle de entradas e saídas de dinheiro; } \\
\text { 6. Cálculos de gastos, lucros e prejuízos; } \\
\text { 7. Identidade e utilização de ferramentas de } \\
\text { 8. Conhecimentos prévios e adquiridos por } \\
\text { cursos e capacitações. }\end{array}$ & $\begin{array}{l}\text { 1. Planejamento para crescimento da categoria e } \\
\text { migração do porte; } \\
\text { 2. Pesquisas pontuais para conhecer a satisfação } \\
\text { dos clientes; } \\
\text { 3. Pagar contas em dias; } \\
\text { 4. Separar finanças pessoais das finanças do } \\
\text { empreendimento; } \\
\text { 5. Legalizar funcionários com carteira assinada. }\end{array}$ \\
\hline
\end{tabular}

Fonte: Elaborado pelos autores (2019)

Portanto, analisando os dados do questionário em consonância aos aspectos teóricos, percebeu-se que o MEI mesmo sendo uma categoria de porte mais simples pode desenvolver boas práticas de gestão. As dimensões da gestão no contexto de microempreendedores individuais pode não ser uma utopia. Assim como os cinco casos analisados, diversos outros no montante de MEI formalizados podem desenvolver também as mesmas práticas gestão ou já terem avançado com outras mais.

\section{Considerações}

Este artigo procurou abordar como temática o microempreendedor individual em seu contexto de práticas de gestão. Com a dinâmica do mercado competitivo os microempreendedores que pretendem crescer como empresa devem entender que a formalização do negócio não é suficiente para prosperidade do empreendimento.

Destaca-se cada vez mais a importância das dimensões de gestão na prática empreendedora. Refletir e questionar as ações de gestão faz com que o empreendedor valorize cada vez mais seu negócio e dedique esforços para ações que colaborem para sustentabilidade do negócio.

Tomando como base os resultados e análise dessa pesquisa, percebeu-se que os microempreendedores que reconhecem possuir práticas de gestão, de fato praticam a maioria. 
Nisso, foi possível perceber quais destas práticas mais se destacam em suas dimensões e quais podem ser potencializadas para o desenvolvimento de uma gestão mais completa.

É importante ressaltar que o estudo apresenta limitações, principalmente porque os resultados não podem ser generalizados e a ferramenta de coleta de dados pode não ter considerados todas as práticas de gestão possíveis, como também as dimensões. Como sugestão, outros estudos podem aderir o mesmo objetivo desta pesquisa com métodos e técnicas quantitativas, ou se qualitativas, com análises longitudinais, observações, entrevistas e etc. Além disso, outros estudos podem abranger a investigação para dimensões como inovação, estratégia, aprendizagem e sustentabilidade.

Espera-se, portanto que o estudo possa contribuir de fato para a construção do campo, impactando positivamente a visão da sociedade, da política e da economia quanto à importância da boa gestão em microempreendedores individuais, trazendo também novas lacunas para outras investigações na mesma temática.

\section{Referências}

ANDRADE, S. P.; BOFF, C. D. S. Ferramentas de planejamento para tomada de decisão aplicadas a um microempreendedor individual (MEI). Revista de Contabilidade, Ciência da Gestão e Finanças, v. 2, p. 57-85, 2014.

BAGGIO, A. F.; BAGGIO, D. K. Empreendedorismo: Conceitos e definições. Revista de empreendedorismo, inovação e tecnologia, v. 1, n. 1, p. 25-38, 2015.

BARDIN, L. Análise de conteúdo. Lisboa: Edições 70, 1979.

BARGAIN, O.; KWENDA, P. Is informality bad? Evidence from Brazil, Mexico and South Africa. Institute for the Study of Labor (IZA), v. 1, n. 4711, p. 48, 2010.

BITENCOURT, C. C. A gestão de competências gerenciais: a contribuição da aprendizagem organizacional. Tese (Doutorado em Administração) - Universidade Federal do Rio Grande do Sul, 2001.

BITTENCOURT, M.; PALMEIRA, E. M. Gestão financeira. Disponível em: http://www.eumed.net/cursecon/ecolat/br/12/bmp.pdf. 2012. Acesso em: 05 de Julho de 2019. BRETTEL, M.; STRESE, S.; FLATTEN, T. C. Improving the performance of business models with relationship marketing efforts - An entrepreneurial perspective. European Management Journal, v. 30, n. 2, p. 85-98, 2012.

BUENO, V. de F. Avaliação de risco na concessão de crédito bancário para micro e pequenas empresas. Dissertação de Mestrado. Programa de Pós-Graduação em Engenharia de Produção Ciências Contábeis. UFSC, Florianópolis, 2003.

CARVALHO, E. de A. A importância do controle de entradas e saídas de caixa para o Microempreendedor Individual (MEI). Trabalho de Conclusão de Curso (Graduação) Universidade Estadual do Sudoeste da Bahia, Vitória da Conquista, 2013.

CORSEUIL, C. H.; NERI, M. C.; ULYSSEA, G. Uma análise exploratória dos efeitos da política de formalização dos microempreendedores individuais. Texto para Discussão, Instituto de Pesquisa Econômica Aplicada (IPEA), 2014.

CORSEUIL, C. H.; REIS, M. C.; BRITO, A. S. Critérios de classificação para ocupação informal: consequências para caracterização do setor informal e para a análise de bem-estar no Brasil. Estudos Econômicos, v. 45, n. 1, p. 5-31, 2015. 
CRESWELL, J. W. Research design: qualitative \& quantitative approaches. London: Sage, 1994.

CRUZ, C. F. Os motivos que dificultam a ação empreendedora conforme o ciclo de vida das organizações: um estudo de caso: Pramp's lanchonete. Dissertação (Mestrado) Universidade Federal de Santa Catarina, Centro Tecnológico. Programa de Pós Graduação em Engenharia de Produção. 2005.

CUSTÓDIO, T. P. A importância do empreendedorismo como estratégia de negócio. Trabalho de Conclusão de Curso (Graduação) - Centro Universitário Católico Salesiano Auxilium - UNISALESIANO, Lins-SP, 2011.

DA ANUNCIAÇÃO, R. M. et al. Análise do controle organizacional de artesãos paraibanos após a formalização no programa microeempreendedor individual. REMIPE-Revista de Micro e Pequenas Empresas e Empreendedorismo da Fatec Osasco, v. 4, n. 2, p. 251-270, 2018.

DA SILVA, R. S.; SPANHOL, F. J.; DE SOUZA, M. V. Uso do mobile learning para o capacitação de microempreendedores individuais. Disponível em: http://www.abed.org.br/congresso2018/anais/trabalhos/8348.pdf. Acesso em: 05 de Julho de 2019.

DAU, L. A.; CUERVO-CAZURRA, A. To formalize or not to formalize: Entrepreneurship and pro-market institutions. Journal of Business Venturing, v. 29, n. 5, p. 668-686, 2014.

DIAS MANGUEIRA, B. G.; LAPA, P. A participação do Microempreendedor Individual (MEI) nas compras governamentais no município do Recife (2016-2017). Caderno Discente, v. 4, n. 1, p. 01-28, 2019.

DOS SANTOS, M. et al. APOIO À DECISÃO DE UM MICROEMPREENDEDOR INDIVIDUAL POR MEIO DO MÉTODO SIMPLEX. Revista de Trabalhos Acadêmicos Lusófona, v. 2, n. 2, p. 305, 2019.

FAJNZYLBER, P; MALONEY, W. F.; MONTES-ROJAS, G. V. Does formality improve micro-firm performance? Evidence from the Brazilian SIMPLES program. Journal of Development Economics, v. 94, n. 2, p. 262-276, 2011.

FARIA, B. S. et al. Perfil Do Microempreendedor Individual: Uma Analise na Cidade de Volta Redonda. Anais... XII Simpósio de Excelência em Gestão e Tecnologia - SEGeT. 2015.

FIGUEIREDO, S.; CAGGIANO, P. C. Controladoria: teoria e prática. 3 ed. São Paulo: Atlas, 2004.

GODOY, A. S. Introdução à pesquisa qualitativa e suas possibilidades. Revista de administração de empresas, v. 35, n. 2, p. 57-63, 1995.

GUY, R. F.; NORVELL, M. The neutral point on a Likert scale. The Journal of Psychology, v. 95, n. 2, p. 199-204, 1977.

KENYON, T.; KAPAZ, E. The informality trap: Tax evasion, finance and productivity in Brazil. Public Policy for the Private Sector Note, v. 301, 2005.

KENYON, T.; KAPAZ, E.. The Informality Trap: Tax Evasion, Finace, and Productivity in Brazil. Public Policy for the Private Sector, v. 301, 2005.

LEONTARIDI, M. Segmented labour markets: theory and evidence. Journal of Economic Surveys, v. 12, n. 1, p. 103-109, 1998. 
LOPES, L. C. et al. Adoção de práticas de controles financeiros e não financeiros por microempreendedores individuais. Gestão e Sociedade, v. 8, n. 21, p. 749-766, 2014.

LUCIAN, R. Repensando o uso da escala Likert: tradição ou escolha técnica. PMKT-Revista Brasileira de Pesquisas de Marketing, Opinião e Mídia, v. 9, n. 1, p. 12-28, 2016.

MANTOVANI, E.; CADONÁ, M. A. Redes Sociais e a Experiência de Formalização de Microempreendedores Individuais. Revista BARU- Revista Brasileira de Assuntos Regionais e Urbanos, v. 4, n. 1, p. 93-111, 2018.

MATURANA, A. C. K. et al. FINANÇAS PESSOAIS: UM ESTUDO DOS MICROEMPREENDEDORES INDIVIDUAIS DA CIDADE DE GIRUÁ-RS. Revista de Administração e Comércio Exterior, v. 1, n. 2, p. 2-18, 2015.

MATURANA, A. C. K.; BAGGIO, D. K. Finanças pessoais: um estudo com os microempreendedores da região noroeste do estado do rio grande do sul1. In: Anais... XXIV Seminário de Iniciação Científica Unijuí. 2016.

MEYER, C. A. Planejamento formal e seus resultados: um estudo de caso. Caderno de

MORAIS, M. C. A.; EMMENDOERFER, M. L. Determinantes socioeconômicos do Microempreendedorismo individual (MEI): evidências e implicações. In: Anais... X EGEPE Encontro de Estudos sobre Empreendedorismo e Gestão de Pequenas Empresas. São Paulo. 2018.

MORAIS, M. C. A.; EMMENDOERFER, M. L. Microempreendedorismo individual (MEI) e seus efeitos sobre as condições sociais em municípios mineiros: um estudo empírico. In: Anais... X EGEPE - Encontro de Estudos sobre Empreendedorismo e Gestão de Pequenas Empresas. São Paulo. 2018.

MUNIZ, K. M.; SILVA, E. D da. A estratégia no contexto (e na mente) do empreendedor. In: Anais... IV EGEPE - Encontro de Estudos Sobre Empreendedorismo e Gestão de Pequenas Empresas. Curitiba, 2005.

NORTH, K.; DA SILVA NETO, E.; CALLE, G. D. Vencendo os desafios do crescimento: o método "aprender a crescer" para pequenas e médias empresas brasileiras. NAVUS - Revista de Gestão e Tecnologia, v. 3, n. 1, p. 06-19, 2013.

OLIVEIRA, A. M de; SANABIO, M. T. Compreendendo o fenômeno do empreendedorismo: uma análise das escolas do Pensamento Empreendedor. In: Anais... IV EGEPE - Encontro de Estudos Sobre Empreendedorismo e Gestão de Pequenas Empresas. Curitiba. 2005.

PELISSARI, A. S. et al. Diagnóstico do uso da inteligência competitiva empreendedora em pequenas empresas da indústria de confecções da cidade de Vila Velha-ES. Revista de Administração da Universidade Federal de Santa Maria, v. 5, n. 2, p. 183-203, 2012. pesquisas em administração, v. 2, n. 5, p. 39-46, 1997.

PIMENTEL, A. A teoria da aprendizagem experiencial como alicerce de estudos sobre desenvolvimento profissional. Estudos de Psicologia, v. 12, n. 2, p. 159-168, 2007.

PONCZEK, V.; ULYSSEA, G.. Is informality an employment buffer? Evidence from the trade liberalization in Brazil. Unpublished Working Paper, 2017. Disponível em: https://ebape.fgv.br/sites/ebape.fgv.br/files/paginas/abr/17/ponczekulysseaintro.pdf. Acesso em: 15 de Setembro de 2019.

PORTAL DO EMPREENDEDOR. O que é ser um MEI? Disponível em: <http://www.portaldoempreendedor.gov.br/temas/quero-ser/formalize-se/O-que-e-ser-ummei. Acesso em: 20 de Setembro de 2019. 
RAMALHO, D. S. Linhas de crédito específicas para o microempreendedor individual como forma de incentivo para aplicação dos negócios. Trabalho de Conclusão de Curso (Graduação) - Universidade Federal de Rondônia - UNIR, 2015.

RAUPP, F. M; BEUREN, I. M. Metodologia da Pesquisa Aplicável às Ciências. Como elaborar trabalhos monográficos em contabilidade: teoria e prática. São Paulo: Atlas, 2006.

SALGADO, J. Corpo miserável, espírito empreendedor: empreendedorismo, pobreza e desemprego no Brasil. Revista em Pauta, v. 10, n. 30, p. 129-147, 2012.

SANTOS, P. da C. F. dos. Uma escala para identificar potencial empreendedor. Tese (Doutorado em Engenharia de Produção) - Universidade Federal de Santa Catarina, Florianópolis, Santa Catarina, 2008.

SEBRAE. Perfil do Microempreendedor Individual 2017. Disponível em: http://datasebrae.com.br/wp-content/uploads/2017/08/Perfil-do-Microempreendedor Individual_2017-v8.pdf. Acesso em: 20 de Setembro de 2019.

SEBRAE. Tire suas dúvidas sobre o MEI (Microempreendedor Individual). Disponível em: https://www.sebrae.com.br/sites/PortalSebrae/artigos/tire-suas-duvidas-sobre-o-meimicroempreendedor-individual,e31c13074c0a3410VgnVCM1000003b74010aRCRD. Acesso em: 25 de Julho de 2019.

SILVA, M. J. F. et al. A percepção econômico-financeira do microempreendedor individual em Goiás. Revista Pensamento Contemporâneo em Administração, v. 8, n. 3, p. 71-85, 2014.

SOUZA, G. H. S. de et al. Marketing informal: Um modelo de comercialização pautado em jeitinho brasileiro, informalidade e empreendedorismo. Revista Brasileira de Marketing, v. 13, n. 3, p. 63-77, 2014.

SOUZA, G. S. et al. Estruturas de comercialização: ações de marketing informal por microempreendedores em uma feira-livre. In: Anais... XI Congresso Nacional de Excelência em Gestão. 2015.

SOUZA, K,E. A necessidade da implementação de mudanças estratégicas em empresas brasileiras de pequeno porte. Dissertação (Mestrado) Programa de Pós-graduação em Engenharia de Produção - Universidade Federal de Santa Catarina. 2013.

TAVARES, B.; FERREIRA, M. A. M.; CARVALHO LIMA, A. A. T. de F. de. Identificação das práticas de gestão das micro e pequenas empresas: construindo uma escala de mensuração. Revista de Negócios, v. 14, n. 4, p. 11-27, 2009.

TEIXEIRA, E. B. A análise de dados na pesquisa científica: importância e desafios em estudos organizacionais. Desenvolvimento em questão, v. 1, n. 2, p. 177-201, 2003.

VEJA. Cresce o número de empreendedores devido desemprego. 2018. Disponível em: https://veja.abril.com.br/economia/com-desemprego-em-alta-numero-de-meis-cresce-quase-

40/; Acesso em: 05 de Julho de 2019

VENTURA, M. M. O estudo de caso como modalidade de pesquisa. Revista SoCERJ, v. 20, n. 5, p. 383-386, 2007.

YIN, R. K. Estudo de caso: planejamento e métodos. Porto Alegre: ARTMED, 2005. 